\title{
DIGESTIBILIDADE APARENTE DE DOIS CULTIVARES DE MILHO, CORTADOS EM DIFERENTES ALTURAS, SUBMETIDOS À ENSILAGEM
}

\author{
(Apparently digestibility of two hybrids corn, cut in different highs, \\ submitted to silage)
}

ROSSI JUNIOR, P. ${ }^{1}$ FUGISAWA, A.C. ${ }^{2}$; SCHOGOR, A.L.B. ${ }^{3}$; MURARO, G.B. ${ }^{4}$

\begin{abstract}
1Professor do Departamento de Zootecnia - UFPR. E-mail: parossi@ufpr.br; ${ }^{2}$ Médica Veterinária, Curitiba/PR; ${ }^{3}$ Zootecnista, Curitiba - PR; ${ }^{4}$ Mestranda do curso de Pós-graduação em Ciências Veterinárias da UFPR.
\end{abstract}

\begin{abstract}
RESUMO - Devido a constante utilização de silagem de milho para alimentação de animais de alto desempenho produtivo, este experimento teve como objetivo avaliar a digestibilidade aparente da silagem de duas variedades de milho (AG 1051 textura farinácea e AG 2020 textura dura), cortados a $20 \mathrm{~cm}$ e $40 \mathrm{~cm}$ de altura do solo. Foram utilizados 8 animais SRD adultos, divididos em 2 blocos, compondo um modelo fatorial. As médias foram testadas pelo teste de Tukey a $5 \%$. A digestibilidade foi calculada utilizando o método de coleta total de excretas. Foram estimados os valores de digestibilidade aparente da matéria seca (MS), extrato etéreo (EE), proteína bruta $(P B)$, fibra em detergente ácido (FDA) e fibra em detergente neutro (FDN). A digestibilidade da MS, EE, PB e FDN foi superior para a variedade AG 1051 cortada a $40 \mathrm{~cm}$ de altura e o FDA não diferiu estatisticamente entre os tratamentos $(P<0,05)$. Sugere-se então, a utilização de cultivares de textura macia e altura de corte mais elevada, quando se busca obter uma silagem de maior digestibilidade.
\end{abstract}

Palavras-chave: híbridos; milho; textura farinácea; textura dura; silagem.

ABSTRACT - Due the increasing utilization of corn silage for animal feeding whit high performance, this experiment objective was evaluates the total digestibility of silage elaborated whit two varieties of corn (AG 1051 floury and AG 2020 flint), cutting in 20 and 40 centimeters of soil. Were utilized 8 animals without defined race, divided in two blocks, composing a factorial model. Tukey test was used to compare treatments means, significance level of $5 \%$. The digestibility was calculated with the total collection of excrete/feaces. Was estimated values of total digestibility of dry matter (DM), ether extract (EE), crude protein (CP), acid detergent fiber (ADF) and neutral detergent fiber (NDF). Digestibility of DM, EE, CP and NDF was higher for AG 1051 cutting in $40 \mathrm{~cm}$, and the ADF no present significant differences between treatments $(P<0.05)$. The utilization of floury hybrids and higher cutting height was suggested.

Key-words: corn; hybrids; floury; flint; silage.

\section{Introdução}

A grande dependência das pastagens e das condições climáticas são as maiores causas da baixa produtividade e da qualidade insatisfatória da produção de bovinos no Brasil. Dessa forma, a intensificação da produção de carne bovina apresenta a necessidade da utilização estratégica de forragens conservadas, principalmente na forma de silagem, em complementação ao manejo de pastagens e em combinação com o uso racional de grãos, resíduos da lavoura ou subprodutos da agroindústria (ROSA et al., 2004).

O milho é um dos cultivares forrageiros mais empregados para a ensilagem no Paraná, sendo seu uso muito difundido entre os pecuaristas na alimentação de vacas leiteiras e em sistemas de produção de gado de corte (SOUZA et al., 2000). Mais de 200 cultivares de milho, para as mais diversas finalidades, são disponibilizados por ano por órgãos de pesquisa governamentais e empresas particulares.

A ênfase no uso de cultivares modernos de milho, mais produtivos e adaptados às condições locais e plantas anatomo-fisiologicamente mais eficientes têm sido apontadas por produtores e técnicos como responsáveis pelos ganhos efetivos em produtividade nessa cultura (NUSSIO, 1991).

Além das características como produtividade, digestibilidade e percentual de espigas nos cultivares de milho utilizados para produção de silagem, a textura do grão (vitreosidade) é outra variável que passa a ser observada na escolha de genótipos utilizados para alimentação de ruminantes. As características relacionadas ao endosperma do grão do milho afetam a degradabilidade do amido no rúmen. Logo, dependendo do genótipo, o milho poderá fornecer em maior ou menor velocidade, energia para a síntese de proteína bacteriana (LOPES et al., 2004).

Dentre algumas classificações de grão de milho, estes podem ser classificados quanto a textura em amiláceos (ou farináceos), duros (ou cristalinos ou vítreos) e dentados. O milho dentado possui endosperma duro nos lados e farináceo no centro do grão. Ao secar, o amido mole reduz seu volume mais

Endereço para correspondência: SCA/UFPR, Rua dos Funcionários, 1540 - CEP 80035-050, Curitiba-PR. 
Digestibilidade aparente de dois cultivares de milho, cortados em diferentes alturas, submetidos à ensilagem

do que as camadas duras e assim se origina a identação, pelo enrugamento do endosperma livre de camadas córneas neste local. As características do milho duro são de apresentar um endosperma duro ou cristalino que ocupa quase todo seu volume, sendo a proporção farinácea muito reduzida (CORRÊA, 2001).

As diferenças observadas na digestibilidade entre as variedades de milho podem estar relacionadas ao teor de grão ou de espiga para um certo estádio de crescimento da planta e à composição morfológica, muito diferente entre os híbridos. Porém, essa variação na digestibilidade resulta, principalmente, das diferenças na digestibilidade da parede celular da planta sem o grão (ZEOULA et al., 2003).

PRADA e SILVA et al. (1999) sugerem que a digestibilidade da porção volumosa deve ser avaliada quando se pretende determinar a qualidade do material ensilado.

A silagem da parte superior das plantas é indicada como opção, sendo obtida pela regulagem da colhedora em plano superior. Essa regulagem tem por objetivo recolher somente a parte superior da planta de milho, constituindo-se numa silagem com alta participação de grãos na matéria seca, apresentando fibras mais digestíveis e de maior conteúdo energético (NUSSIO, 1991).

O objetivo deste trabalho foi avaliar a digestibilidade de silagens elaboradas com dois cultivares comerciais de milho sendo o AG 1051 de textura dentada e o AG 2020 de textura semidura, cortados a $20 \mathrm{~cm}$ e a $40 \mathrm{~cm}$ de altura.

\section{Material e Métodos}

O experimento foi realizado na Fazenda Nantém, no município de Umuarama, a 430 metros de altitude, no noroeste do estado do Paraná, entre os meses de fevereiro a setembro de 2004.

Antes do plantio das variedades foram realizadas análise e correção do solo, e durante a condução da lavoura foram realizados os tratos culturais. Durante 0 período experimental, a ocorrência de chuvas e a oscilação de temperatura foram normais para a região.

Os cultivares comerciais de milhos utilizados para pesquisa foram o AG 1051 e AG 2020. O cultivar AG 1051 é um híbrido de aptidão dupla, de ciclo semiprecoce, de cor amarelada e textura dentada, indicado para uso do grão, silagem da planta inteira e milho verde. O cultivar AG 2020 é um híbrido de aptidão dupla, de ciclo precoce, de cor alaranjada e textura semidura, indicado para uso do grão e silagem da planta inteira (CRUZ e PEREIRA FILHO, 2006).

O plantio das variedades ocorreu no início do mês de fevereiro de 2004, sendo colhido e ensilado com 106 dias de idade, em quatro silos modelo trincheira. Os cortes para ensilagem foram realizados a $20 \mathrm{~cm}$ e a $40 \mathrm{~cm}$ do solo, para as duas variedades. A densidade de plantio utilizada foi de 50 mil plantas por ha.

A abertura dos silos se deu após 70 dias, sendo coletadas amostras para determinação de matéria seca e análise bromatológica.

Para o ensaio de digestibilidade foram utilizadas 8 fêmeas bovinas SRD adultas, divididas em dois grupos de quatro animais. Os animais foram alimentados exclusivamente com silagem de milho, sendo o período de adaptação às dietas de 14 dias, havendo fornecimento controlado e coleta de fezes nos 7 dias seguintes à adaptação, para os dois grupos. As fezes foram identificadas e congeladas para posterior análise.

Os tratamentos foram distribuídos nos grupos conforme QUADRO abaixo.

QUADRO 1 - DISTRIBUIÇÃO DOS TRATAMENTOS AVALIADOS.

\begin{tabular}{|cccc|}
\hline Tratamentos & Grupo & Variedade ensilada & Altura de corte \\
\hline T1 & 1 & AG 1051 & $40 \mathrm{~cm}$ \\
T2 & 2 & AG 1051 & $20 \mathrm{~cm}$ \\
T3 & 2 & AG 2020 & $20 \mathrm{~cm}$ \\
T4 & 1 & AG 2020 & $40 \mathrm{~cm}$ \\
\hline
\end{tabular}

O delineamento experimental utilizado foi o de modelo fatorial, a análise estatística feita pelo programa SANEST (ZONTA e MACHADO, 1984). As médias foram testadas ao nível de $5 \%$ de probabilidade pelo teste de Tukey.

A determinação da matéria seca foi realizada por secagem do material em estufa a $65^{\circ} \mathrm{C}$ por 72 horas, e a análise de proteína bruta e extrato etéreo foi realizada de acordo com a AOAC (1984). A determinação de fibra em detergente neutro (FDN) e fibra em detergente ácido (FDA) foram realizadas de acordo com os métodos descritos por VAN SOEST et al. (1991).
Para a análise de digestibilidade aparente foi realizada coleta total de fezes, sendo que todo o conteúdo diário excretado foi pesado e retirado uma alíquota, para se formar uma amostra composta, conforme os procedimentos descritos por TEIXEIRA (1997).

\section{Resultados e Discussão}

Os dados referentes à composição bromatológica encontram-se na TABELA 1. 
ROSSI JÚNIOR, P. et al.

TABELA 1 - COMPOSIÇÃO BROMATOLÓGICA DE DOIS CULTIVARES DE MILHO (PLANTA), CORTADAS A DUAS ALTURAS DIFERENTES.

\begin{tabular}{rccccc}
\hline Tratamento & MS (\%) & EE (\%) & PB (\%) & FDA (\%) & FDN (\%) \\
\hline AG $105120 \mathrm{~cm}$ & 30,79 & 3,69 & 7,61 & 25,00 & 56,45 \\
AG $105140 \mathrm{~cm}$ & 36,00 & 4,03 & 7,23 & 22,76 & 56,80 \\
AG $202020 \mathrm{~cm}$ & 27,39 & 1,08 & 6,03 & 34,01 & 67,90 \\
AG $202040 \mathrm{~cm}$ & 28,78 & 2,99 & 7,73 & 24,18 & 57,33 \\
\hline
\end{tabular}

Laboratório de Nutrição Animal, UFPR, 2005.

Os dados referentes à digestibilidade das frações estudadas, são apresentados na TABELA 2.

A digestibilidade da matéria seca para o híbrido de textura macia e o híbrido de textura dura não diferiu estatisticamente para a altura de corte de 20 $\mathrm{cm}(\mathrm{P}<0,05)$. Entretanto, apresentou digestibilidade de matéria seca superior para o híbrido de textura macia $(73,55 \%)$ quando comparado ao híbrido de textura dura $(63,59 \%)$, quando cortados a $40 \mathrm{~cm}$ do solo $(P<0,05)$.

O mesmo comportamento ocorreu com a digestibilidade do extrato etéreo, da proteína bruta e da fibra em detergente neutro $(P<0,05)$.

A digestibilidade da fibra em detergente ácido dos híbridos, em ambas alturas de corte, não diferiu estatisticamente entre si $(P<0,05)$.

TABELA 2 - DIGESTIBILIDADE DA MATÉRIA SECA, EXTRATO ETÉREO, PROTEÍNA BRUTA, FIBRA EM DETERGENTE ÁCIDO E FIBRA EM DETERGENTE NEUTRO DOS TRATAMENTOS UTILIZADOS.

\begin{tabular}{cccccc}
\hline Tratamento & MS & EE & PB & FDA & FDN \\
\hline AG $105120 \mathrm{~cm}$ & $69,56^{\mathrm{ab}}$ & $80,01^{\mathrm{ab}}$ & $60,67^{\mathrm{ab}}$ & $56,19^{\mathrm{a}}$ & $58,08^{\mathrm{ab}}$ \\
AG $105140 \mathrm{~cm}$ & $73,55^{\mathrm{a}}$ & $84,74^{\mathrm{a}}$ & $65,83^{\mathrm{a}}$ & $52,98^{\mathrm{a}}$ & $68,05^{\mathrm{a}}$ \\
AG 2020 20 cm & $65,27^{\mathrm{ab}}$ & $79,51^{\mathrm{ab}}$ & $55,79^{\mathrm{ab}}$ & $50,23^{\mathrm{a}}$ & $56,75^{\mathrm{ab}}$ \\
AG 2020 40 cm & $63,59^{\mathrm{b}}$ & $76,53^{\mathrm{b}}$ & $51,80^{\mathrm{b}}$ & $46,90^{\mathrm{a}}$ & $51,44^{\mathrm{b}}$ \\
\hline
\end{tabular}

Letras diferentes, nas colunas, diferem entre si pelo teste de Tukey $(P<0,05)$.

SOUZA et al. (2000) testando diferentes cultivares, com relação à digestibilidade da matéria seca do material ensilado, não observaram diferenças estatísticas $(P>0,05)$, com valores oscilando entre $63,95 \%$ a $69,95 \%$.

MORA et al. (1996) estudaram a digestibilidade aparente da silagem de milho (Zea mays L.), entre outros, para vacas lactantes, encontrando coeficiente de digestibilidade aparente da matéria seca de $61,4 \%$.

MITTELMANN et al. (2005) testaram a digestibilidade in vitro do material ensilado de 21 híbridos de milho recomendados para a região sul do Brasil, encontrando valores entre 64,2 a $67,6 \%$.

RESTLE et al. (2002) comparando a digestibilidade da matéria orgânica in vitro de um mesmo cultivar de milho (AG 5011) em duas alturas de corte distintas (20 e $42 \mathrm{~cm}$ ), sugeriram que a elevação da altura de corte de colheita das plantas de milho conferiu maior valor nutritivo à silagem. Os mesmos autores encontraram um coeficiente de digestibilidade in vitro da matéria orgânica de $58,60 \%$ para altura de corte baixo $(20 \mathrm{~cm})$ e de $66,67 \%$ para altura de corte alto $(42 \mathrm{~cm})$.

Os resultados destes autores diferem do presente estudo, pois os coeficientes de digestibilidade para altura de corte baixo (AG 5011) foi inferior aos encontrados para os dois cultivares estudados. Já para altura de corte alta, a digestibilidade do cultivar AG 5011 apresentou valores mais elevados que o cultivar AG 2020 e valores inferiores ao cultivar AG 1051.

CAETANO (2001), avaliando a digestibilidade de onze cultivares de milho com corte a $5 \mathrm{~cm}$ acima do nível do solo e a $5 \mathrm{~cm}$ abaixo da inserção da primeira espiga, concluiu que a elevação da altura de corte melhorou a qualidade da forragem, em decorrência da redução da participação das frações colmo e folhas, havendo como conseqüência a redução dos componentes da parede celular e aumento nas proporções de grãos, o que determinou o aumento nos valores de digestibilidade da MS e NDT. Os valores encontrados, para altura de corte baixa e alta, foram respectivamente $58,9 \%$ e $62,2 \%$ para MS, $34,14 \%$ e $25,0 \%$ para FDN, $32,2 \%$ e $22,9 \%$ para FDA e $71,3 \%$ e $74,4 \%$ para $\mathrm{PB}$.

PRADA e SILVA et al. (1999) estudaram a digestibilidade in situ do material ensilado de 28 híbridos de milho em 1995/96 e de 21 híbridos de milho em $1996 / 97$, encontrando valores entre 54,3 a $63,8 \%$ para 24 horas de incubação, entre 62,3 a $73,7 \%$ para 48 horas e entre 60,8 a $74,4 \%$ em 72 horas para as variedades testadas em 1995/96 e valores entre 40,8 a $52,9 \%$ para 24 horas, entre 49,5 a $62,2 \%$ para 48 horas e 55,4 a $66,6 \%$ para as variedades testadas em 1996/ 97 (este ano apresentando déficit hídrico), concluindo que é possível se utilizar a digestibilidade da fração volumosa para seleção de híbridos de milho.

Diferenças tão expressivas na digestibilidade da MS da fração volumosa dos híbridos de milho, podem certamente levar a diferenças de consumo de MS e energia digestível, por animais cujo consumo esteja limitado pelo efeito de enchimento da dieta (PRADA e SILVA et al., 1999).

PASSINI et al. (2002) encontraram valores para 
Digestibilidade aparente de dois cultivares de milho, cortados em diferentes alturas, submetidos à ensilagem

digestibilidade in vivo da matéria seca de $74,08 \%$, para PB de $65,85 \%$, para EE de $69,44 \%$ e para FDN de $56,73 \%$.

Philippeau e Michalet-Doureau (1998) citados por CORRÊA (2001) avaliaram a degradação ruminal da matéria seca e do amido de grãos de milho de diferentes texturas (duro ou macio) e diferentes formas de estocagem (fresco ou ensilado) e concluíram que o milho duro foi menos degradado no rúmen que o milho macio, independente da forma de estocagem. A ensilagem aumentou a degradação ruminal da matéria seca e do amido, independente do genótipo. Não houve interação entre genótipo e forma de estocagem, ou seja, a ensilagem aumentou a degradação ruminal do amido na mesma proporção para milho duro ou macio.

\section{Conclusões}

A degradabilidade do material ensilado é de grande importância na seleção de híbridos de milho para silagem.

A associação entre híbridos de milho de textura macia, com altura de corte elevada, deve ser utilizada sempre que possível, pois nutricionalmente apresenta valores de digestibilidade de seus componentes mais elevados.

\section{Referências}

ASSOCIATION OF OFFICIAL ANALYTICAL CHEMISTS. Official methods of analysis of the association of official chemists. 14를 ed. Washington:AOAC, 1984, 1141p.

CAETANO, H. Avaliação de onze cultivares de milho colhidos em duas alturas de corte para produção de silagem. Jaboticabal, 2001. 178p. Tese de Doutorado Faculdade de Ciências Agrárias e Veterinárias, Universidade Estadual Paulista, Jaboticabal.

CORRÊA, C. E. S. Silagem de milho ou cana-de-açúcar e o efeito da textura do grão de milho no desempenho de vacas holandesas. Lavras, 2001. 102p. Tese de Doutorado - Universidade Federal de Lavras.

CRUZ, J.C.; PEREIRA FILHO, I.A. Cultivares de Milho Disponíveis no Mercado de Sementes do Brasil para Safra 2005/06. 2006. Empresa Brasileira de Pesquisa Agropecuária - EMBRAPA - CNPMS. Sete Lagoas - MG. Disponível em www.cnpms.embrapa.br/milho/cultivares. Acesso em 26 jan 2006.

LOPES, F.C.F.; CARNEIRO, J.C.; NOVAES L.P.; VIANA, A.C.; POSSAS, F.P.; OLIVEIRA, J.S.; GONÇALVES, L.C. Avaliação da Degradabilidade Ruminal In Situ da Matéria Seca de Silagens de Milho (Zea mays, L.) com Diferentes Graus de Vitreosidade e com Perfil de Aminoácidos Modificado. In: Congresso Nacional de Milho e Sorgo, XXXV. Anais... Sete Lagoas - MG: Embrapa Milho e Sorgo, 2004. v. 25.
MITTELMANN, A.; SOBRINHO, F. S.; OLIVEIRA, J. S. Avaliação de Híbridos Comerciais de Milho para Utilização como Silagem na Região Sul do Brasil, 2005. Ciência Rural. v. 35, n.3, p. 684-690, 2005.

MORA, P.J.G.; VALADARES FILHO, S.C.; LEÃO, M.I. Digestibilidade Aparente dos Nutrientes e Energia Líquida da Silagem de Milho (Zea mays L.) para Vacas Lactantes. Revista da Sociedade Brasileira de Zootecnia. v. 25, n.2, p. 357-368, 1996.

NUSSIO, L.G. Cultura de Milho para Produção de Silagem de Alto Valor Alimentício. In: 4. SIMPÓSIO SOBRE NUTRIÇÃO DE BOVINOS. 1991, Piracicaba-SP. Anais... Piracicaba: FEALQ, 1991. p. 59-168.

PASSINI, R.; SILVEIRA, A.; RODRIGUES, P. H. M.; CASTRO, A. L.; TITTO, E.A.L.; ARRIGONI, M.B.; COSTA, C. Digestibilidade de Dietas a Base de Grão Úmido de Milho ou de Sorgo Ensilados. Acta Scientiarum, v.24, n.4, p. 1147-1154, 2002.

PRADAe SILVA, L.F.; MACHADO, P.F.; FRANCISCO JUNIOR, J. C. Características Agronômicas e Digestibilidade in situ da Fração Volumosa de Híbridos de Milho para Silagem. Scientia Agraria, v.56, n.1, p.171-184, 1999.

RESTLE, J.; NEUMANN, M.; BRONDANI, I.L. Manipulação da Altura de Corte da Planta de Milho (Zea mays, L.) para Ensilagem, Visando a Produção do Novilho Superprecoce. Revista Brasileira de Zootecnia, ViçosaMG. v. 31, n.3, p. 1235-1244, 2002.

ROSA, J.R.P.; RESTLE, J.; SILVA, J.H.S. Avaliação da silagem de diferentes híbridos de milho (Zea mays, L.) por meio do desempenho de bezerros confinados em fase de crescimento. Revista Brasileira de Zootecnia, ViçosaMG. v. 33, n.4, p. 1016-1028, 2004.

SOUZA, G.A.; FLEMMING, J.S.; FLEMMING, R. Avaliação de Cultivares de Milho para Produção de Silagem de Alta Qualidade. Archives of Veterinary Science, Curitiba-PR. v. 5, p. 107-110, 2000.

TEIXEIRA, J.C. Introdução aos Métodos de Determinação de Digestibilidade em Ruminantes. In: Digestibilidade em Ruminantes. Lavras, MGUFLA-FAEP,1997. Cap 1, p. 7-28.

VAN SOEST, P.J.; ROBERTSON, J.B.; LEWIS, B.A. Methods for dietary fiber, neutral detergent fiber and nonstarch polysaccharides in relation to animal nutrition. Journal of Dairy Science, Champaing, v. 74, n. 10, p. 3583-3597,1991.

ZEOULA, L.M.; BELEZE, J.R.F.; CECATO, U. Avaliação de Cinco híbridos de Milho (Zea mayz, L.) em diferentes Estádios de Maturação. 4. Digestibilidade da Matéria Seca, Matéria Orgânica e Fibra em Detergente Neutro da Porção Vegetativa e Planta Inteira. Revista Brasileira de Zootecnia. v.32. n 3, p. 567-575, 2003.

ZONTA, E.P.; MACHADO, A.A. SANEST - Sistema de Análise para Microcomputadores. Pelotas, RS. Universidade Federal de Pelotas - SEI, 1984.
Recebido para publicação: $\quad$ 23/08/2006 Aprovado: $20 / 12 / 2006$ 